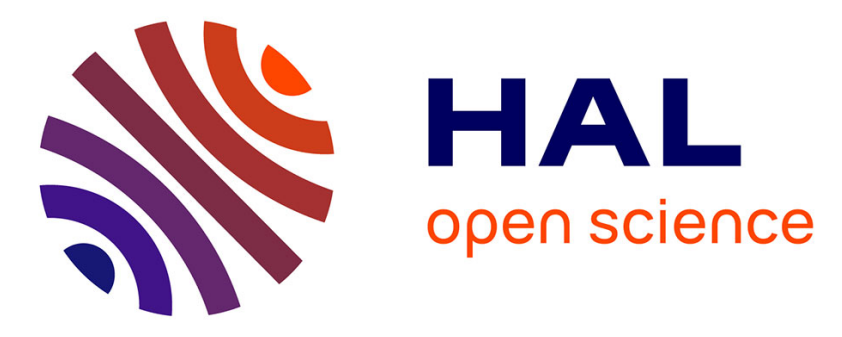

\title{
Online Reviews or Marketer Information? An Eye-Tracking Study on Social Commerce Consumers
} Patrick Mikalef, Kshitij Sharma, Ilias O. Pappas, Michail N. Giannakos

\section{To cite this version:}

Patrick Mikalef, Kshitij Sharma, Ilias O. Pappas, Michail N. Giannakos. Online Reviews or Marketer Information? An Eye-Tracking Study on Social Commerce Consumers. 16th Conference on e-Business, e-Services and e-Society (I3E), Nov 2017, Delhi, India. pp.388-399, 10.1007/978-3-319-68557-1_34 . hal-01768534

\author{
HAL Id: hal-01768534 \\ https://hal.inria.fr/hal-01768534
}

Submitted on 17 Apr 2018

HAL is a multi-disciplinary open access archive for the deposit and dissemination of scientific research documents, whether they are published or not. The documents may come from teaching and research institutions in France or abroad, or from public or private research centers.
L'archive ouverte pluridisciplinaire HAL, est destinée au dépôt et à la diffusion de documents scientifiques de niveau recherche, publiés ou non, émanant des établissements d'enseignement et de recherche français ou étrangers, des laboratoires publics ou privés.

\section{(c)(1)}

Distributed under a Creative Commons Attribution| 4.0 International License 


\title{
Online Reviews or Marketer Information? An eye- tracking study on social commerce consumers
}

\author{
Patrick Mikalef $^{1}$, Kshitij Sharma ${ }^{2}$, Ilias O. Pappas ${ }^{1}$ and Michail Giannakos ${ }^{1}$ \\ ${ }^{1}$ Department of Computer Science, Norwegian University of Science and Technology, Sem \\ Saelandsvei 9, 7491, Trondheim, Norway \\ ${ }^{2}$ CHILI Lab, EPFL, RLC D1 740, Station 20, 1015, Lausanne, Switzerland \\ \{patrick.mikalef, ilpappas, michailg\}@ntnu.no, \\ kshitij.sharma@epfl.ch
}

\begin{abstract}
Driven by the increasing popularity of social commerce sites, this study seeks to examine the information sources and formats that influence consumer intentions to purchase. Specifically, we build on uses and gratifications theory and dual-process theory to determine how user-generated content and marketer-generated content are consumed by users when making a purchase decision. Using an eye-tracking approach on a popular social commerce site with a sample of 23 consumers, we find significant differences in the types of information used for product purchase compared to those omitted. Our study demonstrates that the format and source of information that consumers utilize, as well as the gaze transitions they make between different types of content when browsing, follow different patterns depending on if a product is bought or rejected. We conclude the paper summarizing the findings and drawing theoretical and practical implications that arise.
\end{abstract}

Keywords: Social Commerce, Eye-tracking, Dual-process Theory, User-generated Content

\section{Introduction}

Prompted from the popularity of social media and social networks, social commerce has managed to quickly gain momentum as a subset of e-commerce in the past few years. Social commerce presents certain differences from conventional e-commerce activities by enabling social interactions and the creation and circulation of user generated content on social media platforms [1]. Not surprisingly, social media have attracted the interest of business executives and marketers regarding their potential in gaining a competitive edge [2]. An increasing number of firms are now launching social commerce initiatives, sparked by the promising early outcomes [3]. Yet, while traditionally marketers were in control of the information they provided to consumers through their online venues, in social commerce settings part of this power has been transferred to the consumer [2]. 
The influence of user generated content is becoming ever more important in the decision-making process of individuals and has been a subject of growing interest in research [4]. As more people utilize user generated content on social commerce sites, the process by which they evaluate the credibility and importance of it becomes more complex [5]. This is because user generated content is developed from a very large number of unknown participants world-wide, and the presentation of such a vast amount of information makes decision making an intricate task [6]. In addition, such user generated content is usually presented in several different formats, from extensive reviews, to aggregated information and summarized product ratings [4]. Adding to this, marketers also tend to present product related information in various formats [7].

This vast amount of information, both from individual consumers and marketers, render the buying decision process as quite complicated, since users need to navigate through all content and select the appropriate ones to base their selection [5]. As such, this study builds on uses and gratifications and dual-process theory to understand what type of information users tend to rely on when faced with a purchase dilemma. We use an eye-tracking approach on a popular social commerce site to identify the differences in information consumption between the products selected compared to those that are omitted. Results show that there are significant differences in the utilization of information when consumers are in the process of formulating purchase-related decisions.

The rest of the paper is structured as follows. In section 2 we review the theoretical background which this study builds upon. Next, we develop the research hypotheses, while in section 4 the study design is described. In section 5 the analysis is presented along with results from the eye-tracking experiment. Finally, section 6 discusses the theoretical and practical implications that arise from the results.

\section{Background}

Social commerce websites present unique characteristics compared to physical, or even conventional, online shops. The simultaneous presence of user-generated content (UGC) and content of marketer of products, or else producer-generated content (PGC), creates an interesting environment for consumers who are faced with making purchase decisions based on the different types of information available [5]. While marketers have been able to control the product related information from their side, the affordances present on social commerce sites enable consumers to have strong opinions about products or services and express the openly, without being bound by standards of objectivity [8]. It is widely noted that UGC when negative can have harmful consequences for building and sustaining a brands image, an issue which is compounded since consumers often rely more heavily on UGC when making purchase decisions [9]. While there has been much attention towards the significance of UGC in shaping consumer's behavior, there are very few studies addressing the issue of decision making under the concurrent presence of UGC and PGC. Even more, there is a lack of understanding on how the various formats in which these types of information are presented are utilized by consumers when making purchase decisions [10]. 
To this end we investigate the usefulness of the different forms of information under the uses and gratification theory (UGT). Uses and gratification theory is concerned with how individuals use media, thus, centering on the individual as the main unit of analysis. It has been applied extensively in online environments since it provides one of the most concrete perspectives to explain psychological and behavioral dimensions in mediated communication [11]. The main objective of the uses and gratification theory is to explain the psychological needs that shape why people use media, and what stimuli engage them in performing certain media-based behaviors [11]. One of the main assumptions of UGT is that users are goal-oriented, consequently, when they are faced with a decision choice they select the appropriate media to gratify their goals or needs [12]. In the context of social commerce studies, UGT has been the principal theoretical lens in understanding motives, benefits, and values of consumers [1, 13]. While UGT has been mostly focused on explaining the propensity of use of certain affordances on social commerce websites, there is still limited empirical understanding on the consumption of information sources depending on their origin.

Furthermore, the forma that these information sources are presented in is commonly aggregated at a high level as either UGC or PGC. Yet, many social commerce sites present such information in various formats which result in different means of consuming it when making purchase decisions. Dual-process theory has been widely applied to explain how people are influenced by the different forms of information they are provided with [14]. In the context of online shopping, dual-process theory distinguishes between two different types of influences, normative factors and information factors. Information factors are based on the content of user experiences or marketer descriptions, while normative factors reflect the impact of social aggregation mechanisms available on social commerce websites [4]. According to dual-process theory, informational and normative factors work in parallel in shaping consumers' opinions about products online and finally making purchase-related decisions [4]. In the present study, dual-process theory is applied as the theoretical grounding in explaining the extent to which these two types of information influence the purchase decisions of users of social commerce websites. As such, it provides an influence model based on both the consumers' self-judgment of the information provided by marketers and consumers, and the normative power of aggregated information. Informational influence is derived from information obtained as evidence about reality, and therefore is present in the content, source, and visual cues relating to the product at hand, whether UGC or PGC. On the other hand, normative influence is apparent in aggregated evaluations of the opinions of others [15].

\section{Research Hypothesis}

According to Yale's model, source, message, and receiver are three important informational components in message evaluation [16]. Product related information such as description, price, and technical characteristics are important elements of the message, while visual cues such as images of the product are also found to play a significant role in communication judgment in terms of PGC $[17,18]$. It is also noted that thumbnail 
images produce further stimuli to consumers who tend to enlarge them to identify more information about the product and increase enjoyment [19]. Similarly, consumers tend to rely increasingly more on UGC to gain more information about a product they are interested in, and identify how other users have evaluated it. Such reviews have been subject of much attention since their content, whether positive or negative, is shown to have a significant impact on consumers' intentions to purchase [20]. Despite the significance of such informational components, consumers tend to rely on the opinion of the masses, making normative factors such as average score or ratings of other consumers, an easily accessible resource on which they can safely base their decisions [21]. Hence, we consider the previously mentioned informational and normative factors as important determinants of consumers' intention to make purchase-related decisions.

\subsection{Informational Factors}

\section{Producer Generated Content}

Producer-generated content usually presents some commonalities in terms of presentation and content including several key elements. Firstly, price is a critical component of any purchase decision, with consumers comparing characteristics of products and attempting to determine the ideal price/characteristic balance. Price in combination with brand recognition have been shown to mitigate the risk and influence perception of product quality [21]. In online environments such as that of social commerce, it noted that additional aspects pertinent to the product can help consumers avoid risky purchases [22]. Chen et al. [23] find that the availability of information in a multitude of formats positively contributes to consumers' intentions to purchase online. Productrelated information nevertheless can be presented in various formats. Pictures of the product have been found to influence consumers' behavioral intentions by evoking different levels of emotional imagery [24]. Specifically, Yoo and Kim [25] find that the ability to interact with visual cues, such as zooming into the product, has a significant effect on consumers' buying-related behavior. Consequently, we can infer that the behavior of consumers who are likely to purchase a specific product will demonstrate significant differences in the abovementioned areas compared to when they decide to eliminate it. As such we hypothesize the following:

H1: User gaze on the details of the selected product will be more extensive compared to the ones eliminated.

H2: User gaze on the price of the selected product will be more extensive compared to the ones eliminated.

H3: User gaze on the product description of the selected product will be more extensive compared to the ones eliminated.

H4: User gaze on the product info table of the selected product will be more extensive compared to the ones eliminated.

H5: User gaze on the image of the selected product will be more extensive compared to the ones eliminated. 
H6: User gaze on the zoomed image of the selected product will be more extensive compared to the ones eliminated.

\section{User Generated Content}

While producer generated content has been the predominant means of evaluating the appropriateness of a product with regard to consumer preferences, user generated content on online media have gained increased importance in the decision-making process [5]. Such content can range from negative reviews of the product or service to highly positive, and have been a subject of considerable attention [26]. Evidence to date has been mixed on how consumers factor both positive and negative reviews when making purchase-related decisions [27]. Chevalier and Mayzlin [26] found that products with more positive user generated content had higher sales, although negative user generated content had a stronger impact on sales than positive ones. Similar findings have been noted in other studies where more positive reviews by consumers tended to generate increased sales [28]. On the other hand, negative reviews have been found to be helpful for the decision-making process of consumers since low quality products can be easily detectable and thus eliminated from selection [29]. We therefore hypothesize the following:

H7: User gaze on negative reviews will be more extensive for the eliminated products compared to the selected one.

H8: User gaze on positive reviews will be more extensive for the selected product compared to the ones eliminated.

\subsection{Normative Factors}

Although informational determinants, as discussed above, partially explain how consumers assess and evaluate the product at hand, these do not take into account the aspect of normative influence. In the context of social commerce, various representations of aggregated user generated content are present which are aimed at structuring the opinions of previous buyers. Product rating is a measure which aims to calculate the mean score given by all past buyers towards a specific product, most commonly, on a 5-level scale. In some cases consumers also have access to the number, or percentage of consumers, who rated the product on each score (i.e. how many rated on a level of 1, 2 etc.). These types of representing information generated by users are some of the most important factors when it comes to decision making [28]. Past studies have shown that normative factors such as user generated product rating act on perceived product quality, which in turn influences purchase intention [21]. These findings highlight the importance of social influence mechanisms in the decision making process of consumers on social commerce platforms $[30,31,33,34]$. We therefore hypothesize that:

H9: User gaze on review summary will be more extensive for the selected product compared to the ones eliminated. 


\section{Experiment and Variables}

\subsection{Procedure}

There were 23 participants in the experiment. There were 10 females. The average age was 27.5 years (age std. dev. 7.15 years). All of them had average to high experience with shopping at Amazon. The participants were provided with three Amazon products (electronic fans with remote controls). The products were chosen to be gender neutral so that the gender bias could be eliminated. The simple experimental task was to select one of the fans after carefully examining the information given on each of the pages. All the participants took 10-15 minutes to decide which product they would have bought. During this whole process their gaze was recorded using three SMI eye-tracking glasses at $60 \mathrm{~Hz}$ and two Tobii eye-tracking glasses also at $60 \mathrm{~Hz}$. After careful examination of the data, we excluded four participants from the analysis.

\subsection{Dependent variable}

We distinguish between the products that the participants chose and the others they eliminated. We subsequently call them "selected" and "eliminated", respectively.

\subsection{Process variables}

We extracted a few variables from the eye-tracking data while the participants were selecting the product to buy. We computed the proportion of the total time spent on the specific Area of Interest (AOI). For the rest of the paper, we will use the notion " time spent on..." for the "proportion of time spent on...".

In this section, we present the different AOIs that we used to differentiate the gaze behavior between bought and eliminated products. For the following descriptions, we will refer to the Figure $\mathrm{x} 1$. The actual details in Figure $\mathrm{x} 1$ might vary from the details at the time of data gathering because of time difference between data gathering and writing this contribution.

Gaze on Reviews: We distinguished between the time spent on the review summary (Figure $\mathrm{x} 1$ ) and the individual reviews. We further grouped the individual reviews into positive and negative reviews based on the sentiments they expressed. Following are exemplar reviews:

Example of positive review (4 stars): "Living in So. Cal. I need a fan on me while sleeping. The Optimus does the job, comes with a remote and has a sleep timer. This is easy to clean and has performed well for two years. Why anyone would buy a fan that you cannot easily clean is beyond me. Some of the pricy tower fans cannot be cleaned at all without a major disassembly. The Optimus is reasonably quiet and puts out a good breeze. I own two."

Example of negative review (1 star): "I brought this fan thinking I would not have to buy another. I received this Fan and was very pleased with the look, set up was easy. The first day was fine so I brought another for my sister. Why did I do that this fan 
started clicking and clicking. I adjusted the head every which way this was the hottest part of the summer. Now here I am needing another fan because this one is driving me CRAZY, My sister asked that I not waste my money she'll get her own. REGRET, REGRET, Don't do it to yourself."

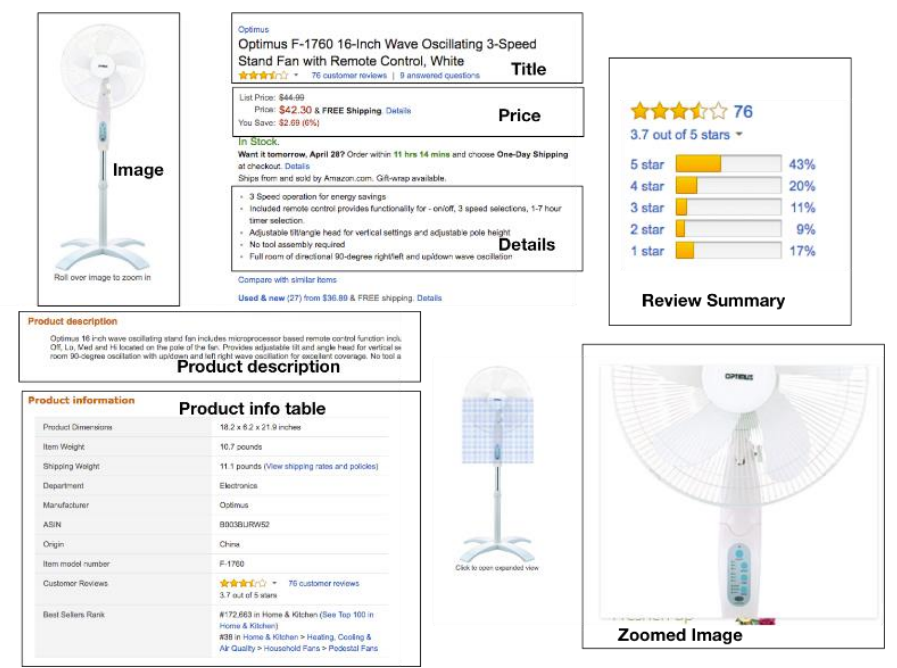

Fig. 1. The different Areas Of Interests (AOIs) defined for the analysis of the eye-tracking data. Most of the AOIs are self-explanatory except a few, for example, the "image" is the image of the product, while the "zoomed image" is the image that pops out when the user hovers the mouse over the image. In addition to these AOIs, we also defined two more AOIs for the positive and negative reviews.

Gaze on product specifications: We distinguished between the time spent on the following parts of the website under product specifications (Figure 1): image, zoomed image, details, product information table, and product description.

Gaze Transitions: Alongside the individual AOIs, we also computed the proportions of the attention shift between different AOIs as the gaze transitions (The complete list of gaze transitions considered in this contribution is provided in Table 1.). These gaze transition provide use with additional information about the information processing behavior. For example, an attention shift among the positive and negative reviews could depict the behavior of comparing the good and bad qualities of the product to have a trade-off between them.

\section{$5 \quad$ Results}

\subsection{Gaze on individual AOIs}

Negative reviews: participants spent significantly less time on the negative reviews of eliminated products as compared to the negative reviews of the selected product. $(\mathrm{t}[31.66]=-2.34, \mathrm{p}=0.02$, Figure 2). 
Table 1. Descriptive statistics and the t-test results for the comparison of time spent on the various AOIs for the selected and eliminated products.

\begin{tabular}{lllll}
\hline AOI & $\begin{array}{l}\text { Selected } \\
\text { Mean(Std. dev) }\end{array}$ & $\begin{array}{l}\text { Eliminated } \\
\text { Mean(Std. dev) }\end{array}$ & $\begin{array}{l}\text { t-test } \\
\text { statistic }\end{array}$ & p-value \\
\hline Image & $0.05(0.04)$ & $0.02(0.02)$ & 2.43 & 0.02 \\
Details & $0.08(0.04)$ & $0.05(0.02)$ & 2.84 & 0.01 \\
Zoomed image & $0.004(0.01)$ & $0.002(0.005)$ & 0.81 & 0.42 \\
Product description & $0.007(0.01)$ & $0.007(0.01)$ & 0.04 & 0.96 \\
Product info. table & $0.03(0.02)$ & $0.03(0.03)$ & -0.43 & 0.67 \\
Review summary & $0.09(0.08)$ & $0.11(0.07)$ & -0.92 & 0.37 \\
Positive reviews & $0.05(0.07)$ & $0.06(0.04)$ & -0.17 & 0.86 \\
Negative reviews & $0.03(0.04)$ & $0.07(0.06)$ & -2.34 & 0.03 \\
\hline
\end{tabular}
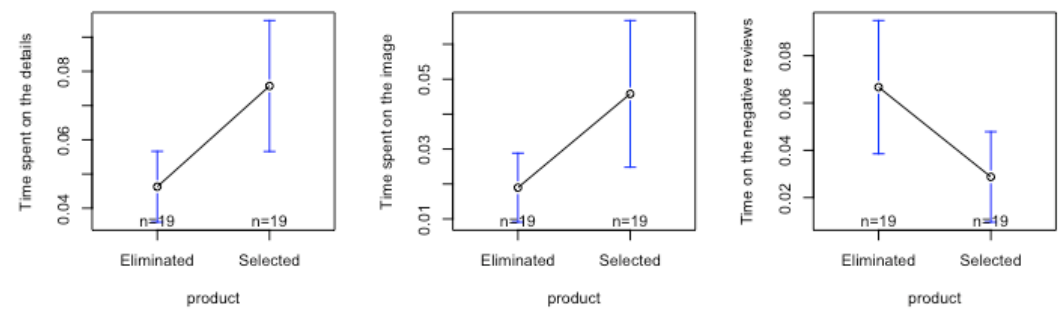

Fig. 2. Gaze on individual AOIs, blue bars show 95\% confidence intervals.

Positive reviews: we observed no difference in the time spent on the positive reviews of eliminated products and the time spent on the positive reviews of the selected product $(\mathrm{t}[=31.67]=-0.17, \mathrm{p}=0.86)$.

Review summary: Similar to the positive reviews for the products there was no significant difference in the time spent on the review summaries of the eliminated and selected products $(\mathrm{t}[32.77]=-1.10, \mathrm{p}=0.27)$.

Details: time spent on the details of the selected products was significantly more than that for eliminated products $(\mathrm{t}[27.68]=2.84, \mathrm{p}=0.008$, Figure 2$)$.

Images: similar to the details, participants spent more time on the image of selected product than the images of eliminated products $(\mathrm{t}[25.58]=2.42, \mathrm{p}=0.02$, Figure 2$)$.

Zoomed images: there was no significant difference between the times spent on the zoomed images of the products $(\mathrm{t}[29.01]=0.80, \mathrm{p}=0.42)$.

Product info. table: we observed no significant difference between the times spent on the products' information tables $(\mathrm{t}[34.00]=0.04, \mathrm{p}=0.96)$.

Product description: there was no significant difference between the times spent on the products' descriptions $(\mathrm{t}[35.29]=-0.43, \mathrm{p}=0.66)$. 


\subsection{Gaze Transitions}

Table 2. Descriptive statistics and the t-test results for the comparison of gaze transitions between the various AOIs for the selected and eliminated products.

\begin{tabular}{lllll}
\hline Transition & $\begin{array}{l}\text { Selected } \\
\text { Mean (Std. dev) }\end{array}$ & $\begin{array}{l}\text { Eliminated } \\
\text { Mean (Std. dev) }\end{array}$ & $\begin{array}{l}\text { t-test } \\
\text { statistic }\end{array}$ & p-value \\
\hline $\begin{array}{l}\text { Reviews } \\
\text { (positive-negative) }\end{array}$ & $0.07(0.10)$ & $0.17(0.20)$ & -2.07 & 0.05 \\
$\begin{array}{l}\text { Review summary- } \\
\text { Positive review }\end{array}$ & $0.16(0.23)$ & $0.09(0.13)$ & 1.02 & 0.31 \\
$\begin{array}{l}\text { Review summary- } \\
\text { Negative review }\end{array}$ & $0.11(0.16)$ & $0.23(0.16)$ & -2.29 & 0.03 \\
Review summary-Price & $0.01(0.04)$ & $0.01(0.03)$ & 0.42 & 0.67 \\
Price-Details & $0.22(0.23)$ & $0.22(0.15)$ & 0.13 & 0.90 \\
Price-Image & $0.13(0.12)$ & $0.14(0.15)$ & -0.41 & 0.68 \\
$\begin{array}{l}\text { Image-Details } \\
\text { Review summary-Details }\end{array}$ & $0.10(0.06)$ & $0.06(0.06)$ & 2.14 & 0.04 \\
\hline
\end{tabular}

Among reviews (negative-positive): the gaze transitions among the positive and the negative reviews for the eliminated products were significantly more than those for the selected product $(\mathrm{t}[26.80]=-2.07, \mathrm{p}=0.05$, Figure 3$)$.

Positive reviews and review table: there was no significant difference between transitions between the review table and the positive reviews $(\mathrm{t}[27.93]=1.02, \mathrm{p}=0.31)$.

Negative reviews and review table: the transitions between the negative reviews and the review table for the eliminated products were significantly higher than those for the selected product $(\mathrm{t}[35.99]=-2.29, \mathrm{p}=0.03$, Figure 3$)$.

Price and review table: there was no difference in gaze transitions between the price and the review table for eliminated and selected products $(\mathrm{t}[34.82]=0.42, \mathrm{p}=0.67)$.

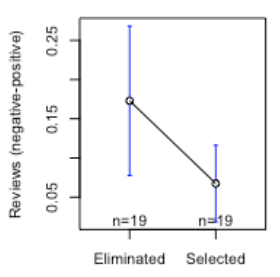

Product

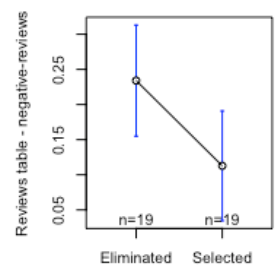

Product

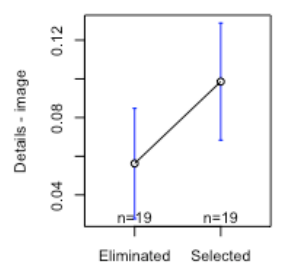

Product

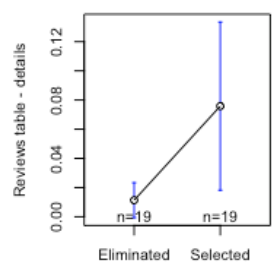

Product

Fig. 3. Gaze transitions between AOIs, $95 \%$ confidence intervals.

Details and review table: the transitions between the details and the review table for the selected product were significantly higher than those for the eliminated products $(\mathrm{t}[19.55]=2.30, \mathrm{p}=0.03$, Figure 3$)$.

Image and details: the transitions between the image and the details for the eliminated products were significantly lower than those for the selected product $(\mathrm{t}[35.87]=2.30$, $\mathrm{p}=0.04$, Figure 3). 
Price and details: we observed no difference in the gaze transitions between the price and the details for the eliminated and selected products $(\mathrm{t}[30.62]=0.13, \mathrm{p}=0.90)$.

Price and image: there was no difference in the gaze transitions between the price and the review table for the eliminated and selected products $(\mathrm{t}[35.13]=-0.41, \mathrm{p}=0.68)$.

\section{Discussion}

We presented the results from 19 participants deciding over three products to choose from. The participants were presented with both the PGC (title, price, image, details, product info. table) and UGC (positive and negative reviews). The information presented on the Amazon pages for the three products could also be divided in informative (PGC and UGC) and normative (review summary) factors.

The results show that a few of the informative, both PGC and UGC, factors play an influential role in product selection. For PGC, the participants spent more time on the details (H1 confirmed) and the image (H5 confirmed) of the selected products than the eliminated ones. However, there was no difference between the times spent on the product info. table $(H 4)$, the price $(H 2)$, the zoomed image $(H 6)$, or the product description (H3). The root cause for this could be attributed to the information content of these PGC. The details, product description, and the product info. table, had replicated information. The easiest way to receive information was to read the details of products, as it was easy to compare the details with the image of the product. This fact is evident from the analysis of gaze transitions between the details and image, which were higher for the selected product than the eliminated ones. This could also be the reason that almost nobody paid much attention to the zoomed image as well.

Concerning the UGC, we found that the negative reviews had more influence while eliminating a product ( $H 7$ confirmed) than the influence of positive reviews while selecting one $(H 8)$. One plausible reason for this could be the difference in the amount of information provided in the negative and positive reviews. All the three products had comparable number of both types of reviews. However, the negative reviews for all the products were extensive in terms of problems faced by the users and were often accompanied by the phrases like "REGRET" and "BUYER BEWARE" in the title of the reviews. On the other hand the positive reviews were shorter than the negative reviews and often contained the satisfactory sentences about the products.

The results show that while considering the individual information pieces the time spent on normative factor is not a distinctive influential mechanism in our study ( $H 9$ not supported). However, the combination of the normative information with the informational factors had an influence on the choice of the product. For example, gaze transitions between the review summary (normative) and the negative reviews (informational, UGC) helped eliminating the products. While the gaze transitions between the review summary (normative) and the product details (informational, PGC) helped selecting the product. 


\section{References}

1. Mikalef, P., Giannakos, M., Pateli, A.: Shopping and word-of-mouth intentions on social media. Journal of theoretical and applied electronic commerce research 8, 17-34 (2013)

2. Zhou, L., Zhang, P., Zimmermann, H.-D.: Social commerce research: An integrated view. Electronic commerce research and applications 12, 61-68 (2013)

3. Stephen, A.T., Toubia, O.: Deriving value from social commerce networks. Journal of marketing research 47, 215-228 (2010)

4. Cheung, M.Y., Luo, C., Sia, C.L., Chen, H.: Credibility of electronic word-of-mouth: Informational and normative determinants of on-line consumer recommendations. International Journal of Electronic Commerce 13, 9-38 (2009)

5. Cheong, H.J., Morrison, M.A.: Consumers' reliance on product information and recommendations found in UGC. Journal of Interactive Advertising 8, 38-49 (2008)

6. Mikalef, P., Giannakos, M.N., Pateli, A.G.: Exploring the Business Potential of Social Media: An Utilitarian and Hedonic Motivation Approach. In: Bled eConference, pp. 21. (2012)

7. Yadav, M.S., De Valck, K., Hennig-Thurau, T., Hoffman, D.L., Spann, M.: Social commerce: a contingency framework for assessing marketing potential. Journal of Interactive Marketing 27, 311-323 (2013)

8. Bruhn, M., Schoenmueller, V., Schäfer, D.B.: Are social media replacing traditional media in terms of brand equity creation? Management Research Review 35, 770-790 (2012)

9. Luo, X., Zhang, J., Duan, W.: Social media and firm equity value. Information Systems Research 24, 146-163 (2013)

10. Trusov, M., Bucklin, R.E., Pauwels, K.: Effects of word-of-mouth versus traditional marketing: findings from an internet social networking site. Journal of marketing 73, 90-102 (2009)

11. Ko, H., Cho, C.-H., Roberts, M.S.: Internet uses and gratifications: A structural equation model of interactive advertising. Journal of advertising 34, 57-70 (2005)

12. Limayem, M., Cheung, C.M.: Predicting the continued use of Internet-based learning technologies: the role of habit. Behaviour \& Information Technology 30, 91-99 (2011)

13. Tsai, W.-H.S., Men, L.R.: Consumer engagement with brands on social network sites: a cross-cultural comparison of China and the USA. Journal of Marketing Communications 23, 2-21 (2017)

14. Cheung, C.M., Thadani, D.R.: The impact of electronic word-of-mouth communication: A literature analysis and integrative model. Decision support systems 54, 461-470 (2012)

15. Filieri, R.: What makes online reviews helpful? A diagnosticity-adoption framework to explain informational and normative influences in e-WOM. Journal of Business Research 68, 1261-1270 (2015)

16. Hovland, C.I., Janis, I.L., Kelley, H.H.: Communication and persuasion; psychological studies of opinion change. (1953)

17. Chang, T.-Z., Wildt, A.R.: Price, product information, and purchase intention: An empirical study. Journal of the Academy of Marketing science 22, 16-27 (1994)

18. Wells, J.D., Valacich, J.S., Hess, T.J.: What signal are you sending? How website quality influences perceptions of product quality and purchase intentions. MIS quarterly 35, 373$396(2011)$

19. Kim, J., Fiore, A.M., Lee, H.-H.: Influences of online store perception, shopping enjoyment, and shopping involvement on consumer patronage behavior towards an online retailer. Journal of retailing and Consumer Services 14, 95-107 (2007) 
20. Pan, Y., Zhang, J.Q.: Born unequal: a study of the helpfulness of user-generated product reviews. Journal of Retailing 87, 598-612 (2011)

21. Flanagin, A.J., Metzger, M.J., Pure, R., Markov, A., Hartsell, E.: Mitigating risk in ecommerce transactions: perceptions of information credibility and the role of user-generated ratings in product quality and purchase intention. Electronic Commerce Research 14, 1$23(2014)$

22. Chiu, C.M., Wang, E.T., Fang, Y.H., Huang, H.Y.: Understanding customers' repeat purchase intentions in B2C e-commerce: the roles of utilitarian value, hedonic value and perceived risk. Information Systems Journal 24, 85-114 (2014)

23. Chen, J., Teng, L., Yu, Y., Yu, X.: The effect of online information sources on purchase intentions between consumers with high and low susceptibility to informational influence. Journal of Business Research 69, 467-475 (2016)

24. Flores, W., Chen, J.-C.V., Ross, W.H.: The effect of variations in banner ad, type of product, website context, and language of advertising on Internet users' attitudes. Computers in Human Behavior 31, 37-47 (2014)

25. Yoo, J., Kim, M.: The effects of online product presentation on consumer responses: A mental imagery perspective. Journal of Business Research 67, 2464-2472 (2014)

26. Chevalier, J.A., Mayzlin, D.: The effect of word of mouth on sales: Online book reviews. Journal of marketing research 43, 345-354 (2006)

27. Dhar, V., Chang, E.A.: Does chatter matter? The impact of user-generated content on music sales. Journal of Interactive Marketing 23, 300-307 (2009)

28. Forman, C., Ghose, A., Wiesenfeld, B.: Examining the relationship between reviews and sales: The role of reviewer identity disclosure in electronic markets. Information Systems Research 19, 291-313 (2008)

29. Lee, J., Park, D.-H., Han, I.: The effect of negative online consumer reviews on product attitude: An information processing view. Electronic commerce research and applications 7, 341-352 (2008)

30. Flanagin, A.J., Metzger, M.J.: Trusting expert-versus user-generated ratings online: The role of information volume, valence, and consumer characteristics. Computers in Human Behavior 29, 1626-1634 (2013)

31. Mikalef, P., Pappas, I.O., Giannakos, M.N.: Value co-creation and purchase intention in social commerce: The enabling role of word-of-mouth and trust. In: Americas Conference on Information Systems AMCIS. (2017)

32. Pappas, I.O, Mikalef, P., Giannakos, M,N., Pavlou., P.A.: Value co-creation and trust in social commerce: An fsQCA approach. In: European Conference on Information Systems ECIS. (2017)

33. Mikalef, P., Pappas, I.O., Giannakos, M.: Consumer Intentions on Social Media: A fsQCA Analysis of Motivations. In: Conference on e-Business, e-Services and e-Society, pp. 371-386. Springer, (2016) 